\title{
Revision surgery in thoracic disc herniation
}

\author{
Stephan Dützmann ${ }^{1}\left[\right.$ D $\cdot$ Roli Rose $^{1} \cdot$ Daniel Rosenthal ${ }^{1}$
}

Received: 3 June 2019 / Revised: 24 October 2019 / Accepted: 29 October 2019 / Published online: 16 November 2019

(c) The Author(s) 2020, corrected publication Jan 2020

\begin{abstract}
Purpose Surgical treatment failures or strategies for the reoperation of residual thoracic disc herniations are sparsely discussed. We investigated factors that led to incomplete disc removal and recommend reoperation strategies.

Methods As a referral centre for thoracic disc disease, we reviewed retrospectively the clinical records and imaging studies before and after the treatment of patients who were sent to us for revision surgery for thoracic disc herniation from 2013 to 2018. Results A total of 456 patients were treated from 2013 to 2018 at our institution. Twenty-one patients had undergone previously thoracic discectomy at an outside facility and harboured residual, incompletely excised and symptomatic herniated thoracic discs. In 12 patients (57\%), the initial symptoms that led to their primary operation were improved after the first surgery, but recurred after a mean of 2.8 years. In seven patients (33\%) they remained stable, and in two cases they were worse. All patients were treated via all dorsal approaches. In all 21 cases, the initial excision was incomplete regarding medullar decompression. All of the discs were removed completely in a single revision procedure. After mean follow-up of 24 months (range 12-57 months), clinical neurological improvement was demonstrated in seven patients, while three patients suffered a worsening and 11 patients remained stable.

Conclusion Our data suggest that pure dorsal decompression provides a short relief of the symptoms caused by spinal cord compression. Progressive myelopathy (probably due to mechanical and vascular deficits) and scar formation may cause worsening of symptoms.
\end{abstract}

\section{Graphic abstract}

These slides can be retrieved under Electronic Supplementary Material.
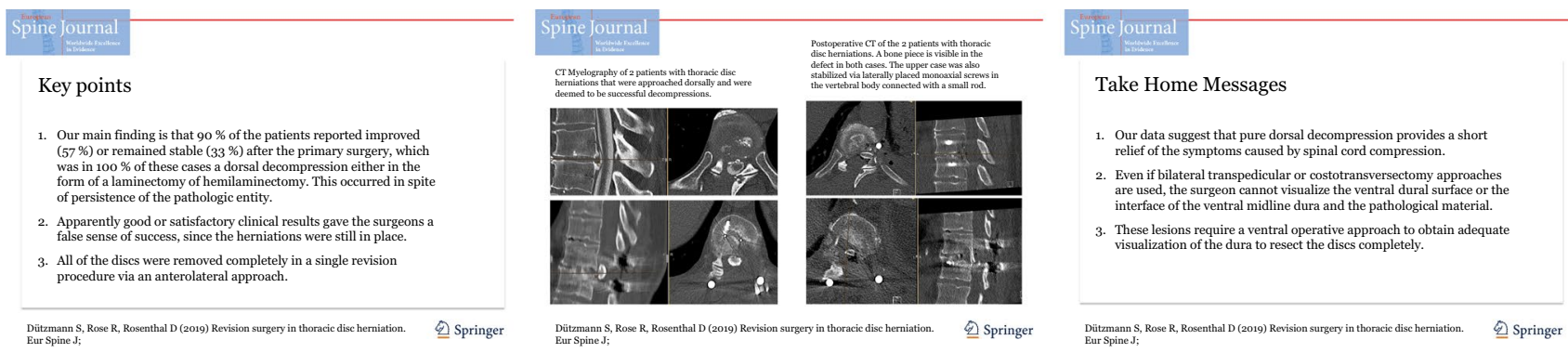

Keywords Thoracic disc disease $\cdot$ Revision surgery $\cdot$ Thoracoscopy $\cdot$ Endoscopy

The original version of this article was revised due to a retrospective Open Access order.

Stephan Dützmann and Roli Rose have contributed equally to this work.

Electronic supplementary material The online version of this article (https://doi.org/10.1007/s00586-019-06212-w) contains supplementary material, which is available to authorized users.

Extended author information available on the last page of the article

\section{Introduction}

The incidence of surgically treated thoracic herniations in the USA is approximated to be $1: 116,338$ [1]. Disc herniations at the thoracic spine can be difficult to remove. Especially giant and calcified herniations and those that extend intradurally pose a formidable challenge to the spine surgeon. 
Numerous reports were published in the last decades analysing retrospective case series and describing their results using or comparing it to other techniques. Choosing the right approach to these lesions thus remains in the focus of the debate. While some researchers advocate to consider the surgeons experience [2,3], the scientific question for the best treatment strategy thereby remains unanswered.

Laminectomy was abandoned during the last 30 yearswith exceptions [4, 5] - and anterolateral transthoracic approaches gained popularity [4, 6-9]. Adequate invasive techniques and instruments have been developed for thoracic and lumbar approaches popularizing the principle of approaching the thoracic spine anterolaterally. However, few articles have been published in the literature dealing with strategies for the reoperation of residual or recurrent thoracic disc herniations [10-13].

We aimed to examine the factors that might lead to incomplete disc removal and recommend strategies in the case of reoperation to ensure complete removal of these lesions while causing minimal morbidity.

\section{Methods}

Between January 2013 and December 2018, 456 consecutive patients were treated at our institution with the diagnosis symptomatic thoracic disc herniation. Twenty-one patients who had previously undergone thoracic discectomy elsewhere harboured a residual, incompletely excised symptomatic herniated thoracic disc, representing $4.8 \%$ of our total patients.

Our preferred method of treatment is the anterior thoracic discectomy. It has been described previously [6]. Briefly, the rib head and pedicle are removed to expose the dura. A cavity is created in the dorsal disc space and vertebral body to provide enough working space to move the disc material away from the spinal canal, thereby facilitating the entry of any tools into the epidural space. This approach is done transthoracic from Th3 to Th10 and retropleural from Th10 to Th12, as has been shown by Berjano et al. [14].

Data analysis included clinical symptoms at admission, diagnostic studies, residual disc material, reoperative strategies, and clinical outcome of the patients. Pre-operative CT-myelography and MRI were obtained routinely. Postoperative assessment included clinical examination, plain $\mathrm{X}$-rays, computerized tomography (CT) and/or magnetic resonance (MR) controls; all images were evaluated by the authors and by independent radiologists for medullar integrity and the extent of spinal canal decompression achieved.

IRB approval was obtained from the local medical board.

\section{Results}

Mean age of the 21 patients was 53 years (range 30-65 years). There were 11 female and 10 male patients. The mean follow-up time was 24 months (range 12-57 months).

The surgical procedures first performed to treat thoracic disc herniations included 12 hemi-laminectomies, six laminectomies, one laminectomy with fusion and two transpedicular or costotransversectomy approaches (Fig. 1). There were 15 centrally located calcified or ossified discs and six soft disc herniations (Fig. 1). In all cases, the initial aim of complete excision was unsuccessful. The locations of the disc herniations are provided in Table 1.

Two patients that were worse after the initial surgery had centrally located calcified disc herniations. All of these cases were extradural.

The mean time interval between the initial surgery and reoperation was 3.75 years (range 1 month-9 years).

In 12 patients (57\%), the initial symptoms that led to their primary operation improved after the first surgery, but recurred after a mean of 2.8 years. In seven $(33 \%)$ patients, the initial symptoms were unchanged and in two patients the initial symptoms worsened after the first surgery.

The patients' primary symptoms at the time of reoperation included persistence or worsening of radicular or dorsal pain (eight patients) progressive or persistent myelopathy due to spinal cord compression (seven patients), persistent pain and improved myelopathy (four patients), new myelopathy and improved pain (two patients). Five patients with myelopathic symptoms complained additionally about urinary incontinence.

In all 21 cases of reoperation, an anterolateral approach was performed using video-assisted thoracoscopy or endoscopy (in case of retropleural approaches).

Of the 21 patients, 20 also required additional ventral spinal reconstruction and internal fixation procedures to restore or maintain spinal column stability.

One patient had a revision procedure 2 years after the revision surgery because she suffered a recurrent disc herniation at the same level.

All of the discs were removed completely in a single revision procedure.

No case of CSF leak occurred.

Clinical improvement of neurological function was demonstrated in seven patients, while three patients suffered a worsening of their neurologic symptoms and 11 patients remained stable. Pain in the form of dorsal pain or radicular pain improved in seven patients, worsened in one patient, turned up de novo in three patients and 
(a)

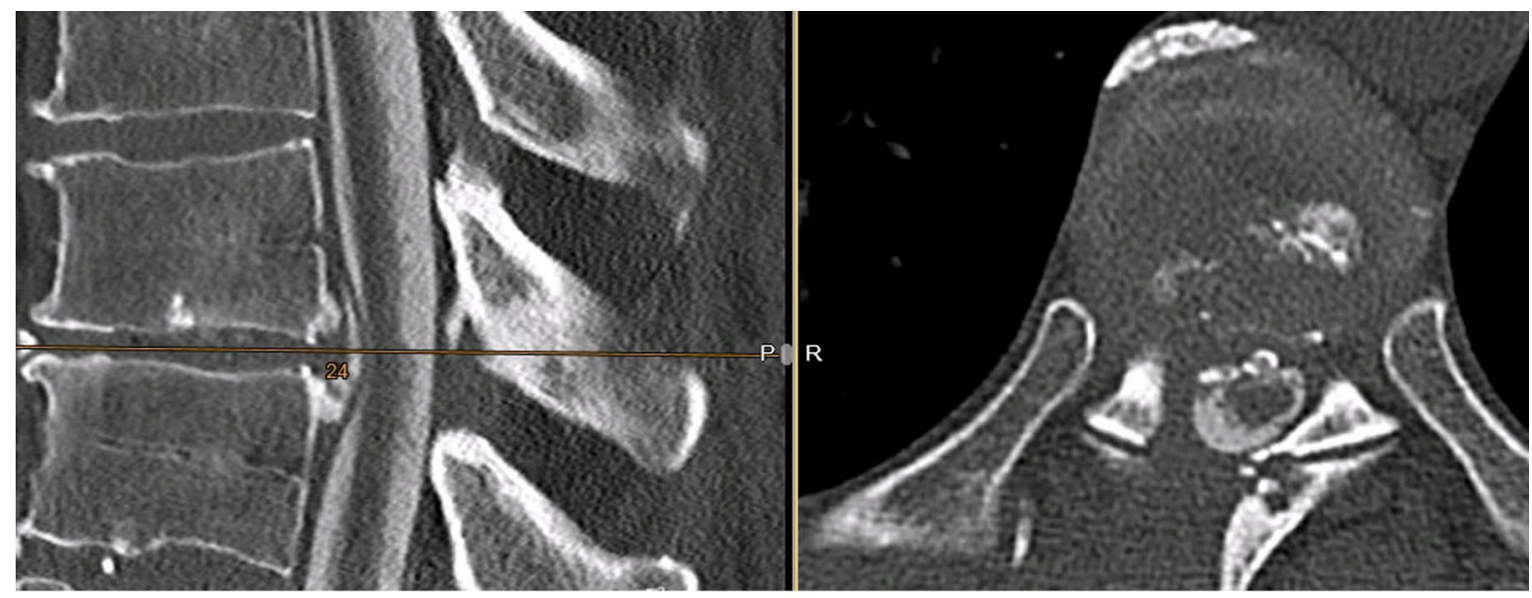

(b)

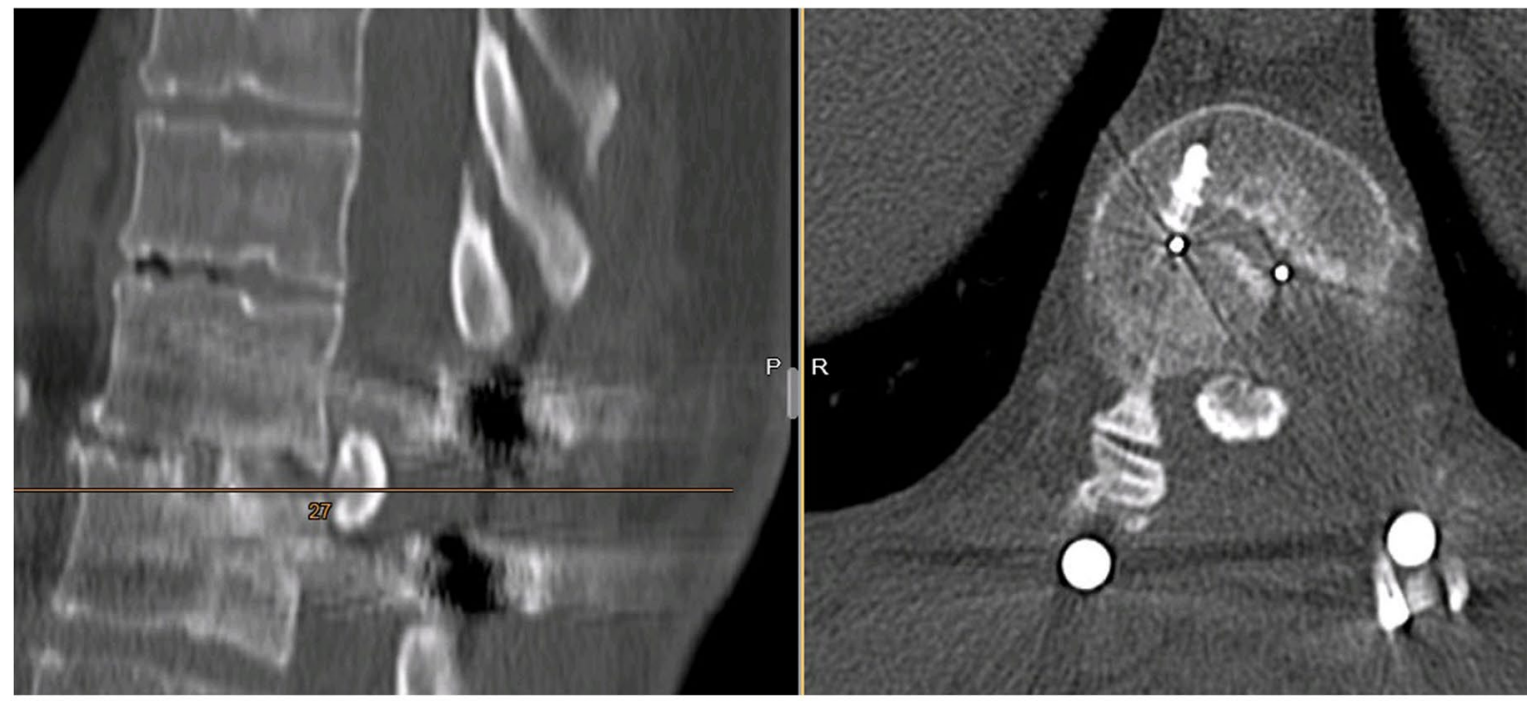

(c)

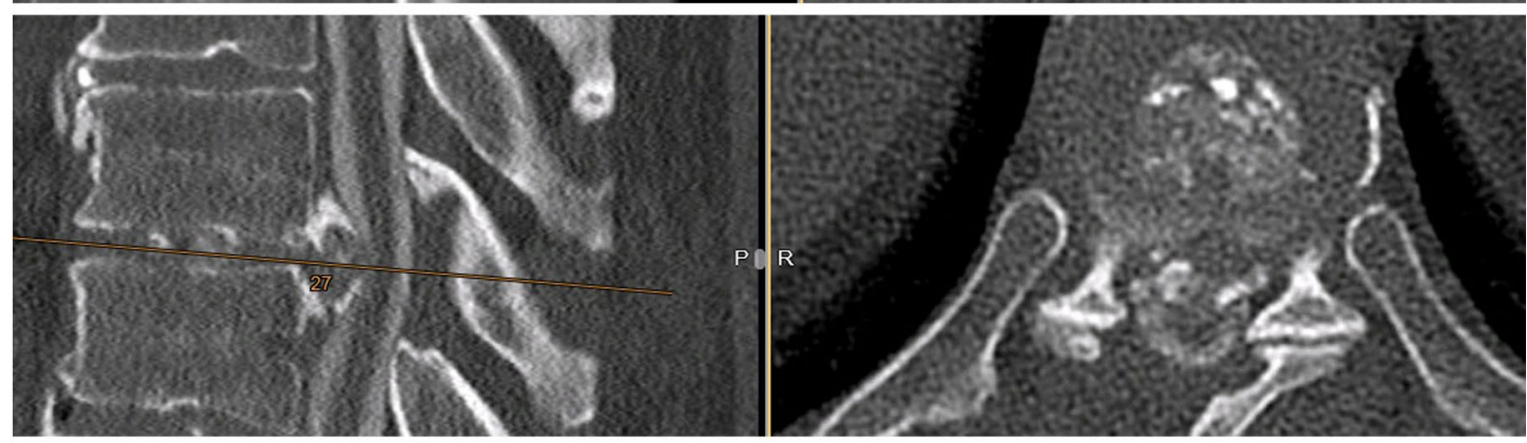

(d)
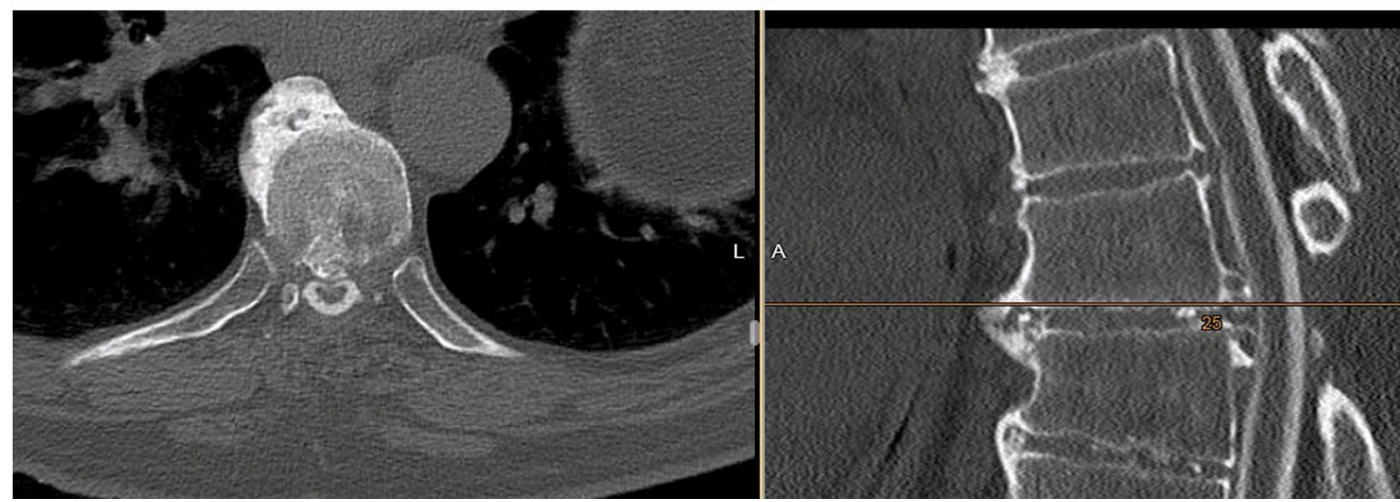

Fig. 1 a-f Six examples of CT-myelography of patients after initial dorsal approaches who harboured residual discs 
(e)

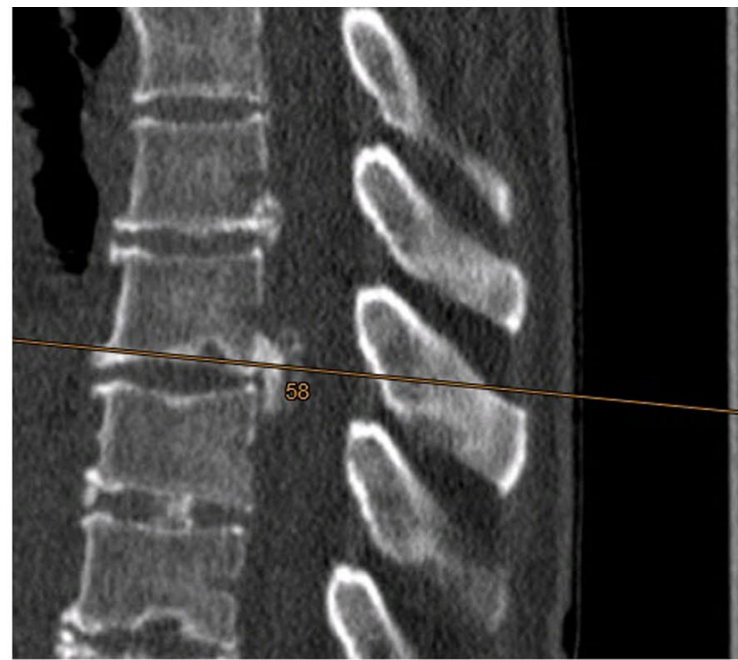

(f)

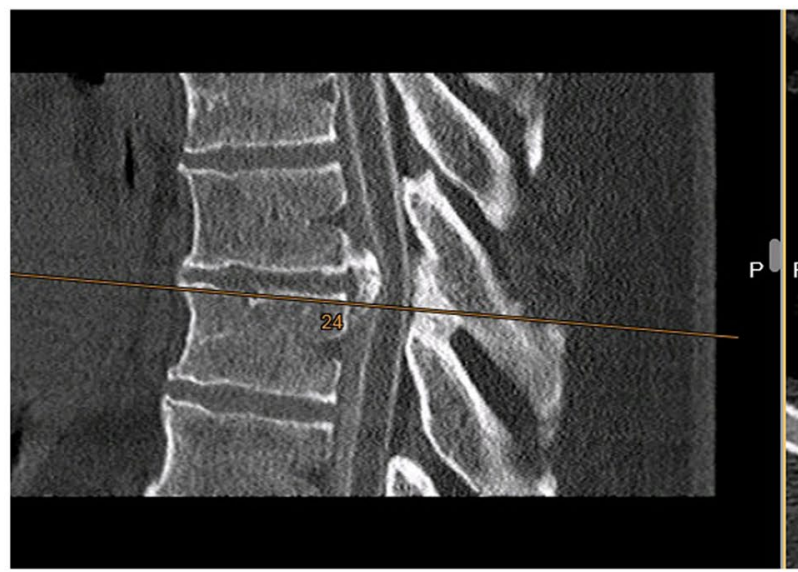

(g)

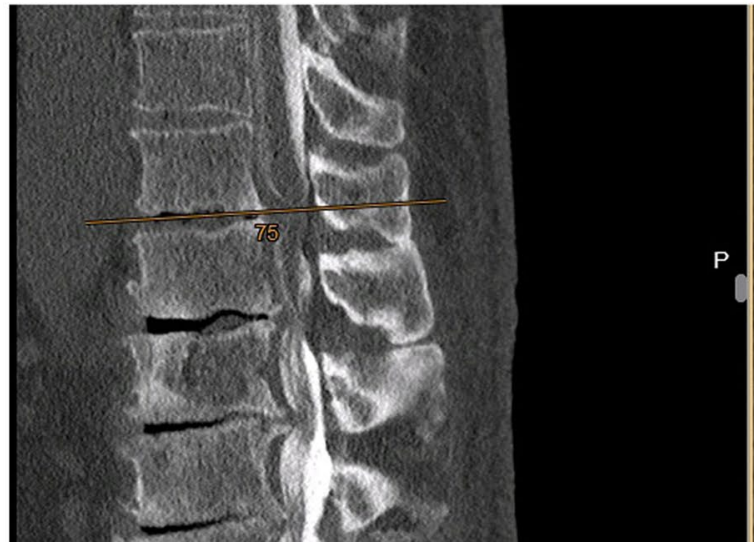

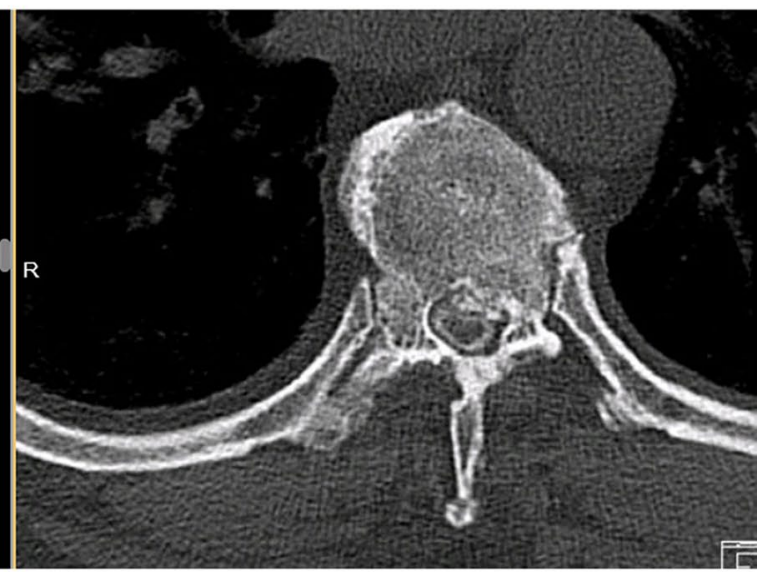
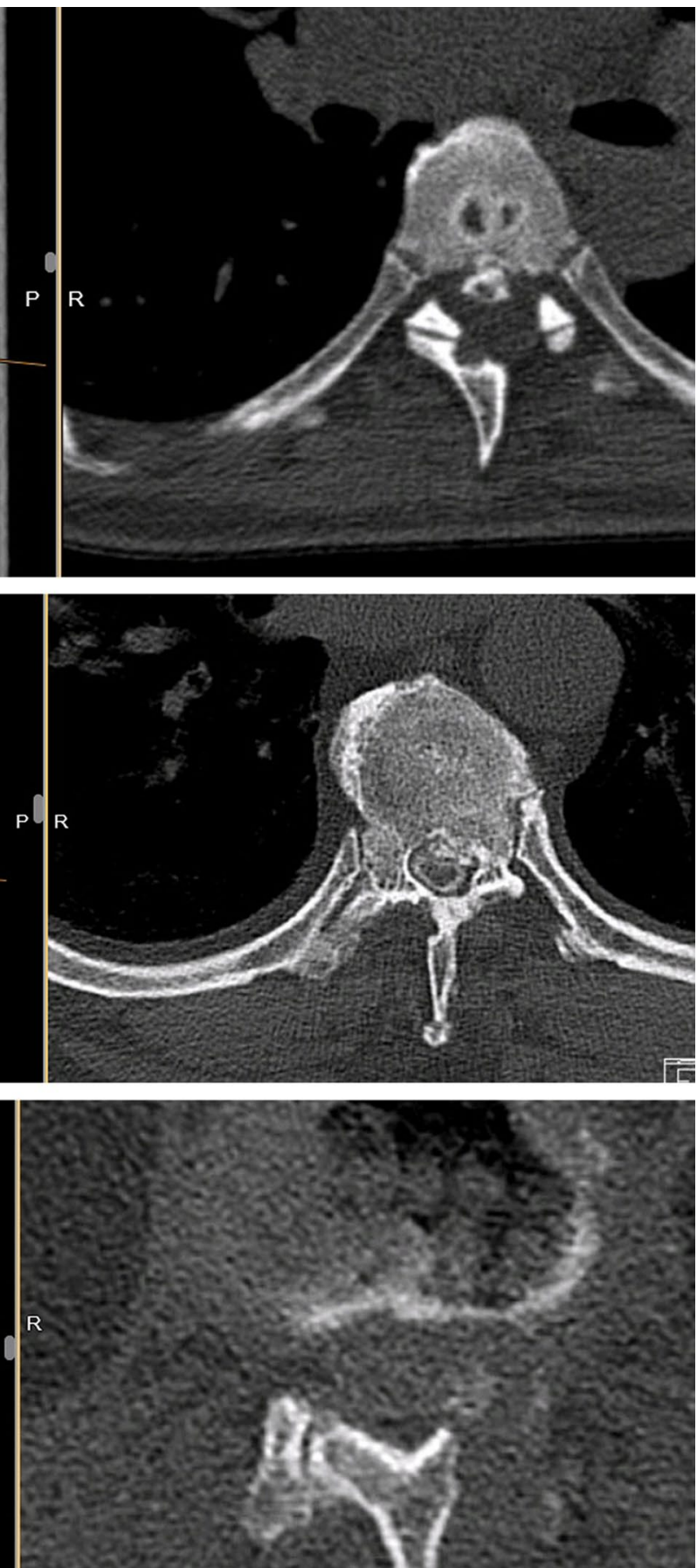

Fig. 1 (continued)

remained stable or non-changed in ten patients. There were no cases of non-union or delayed spinal instability. Post-operative imaging studies obtained in all patients revealed that a complete decompression of the spinal cord and nerve roots had been achieved (Fig. 2).

\section{Discussion}

This is the largest series on revision surgeries for thoracic disc herniation reported so far. The resection of herniated thoracic discs can present formidable technical difficulties, especially if the discs are calcified, ossified, large, centrally 
Table 1 Overview of the affected thoracic levels in our patient population

\begin{tabular}{ll}
\hline $\begin{array}{l}\text { Level of disc hernia- } \\
\text { tion }\end{array}$ & $\begin{array}{l}\text { No. of } \\
\text { patients }\end{array}$ \\
\hline TH $2 / 3$ & 1 \\
TH 3/4 & 0 \\
TH 4/5 & 0 \\
TH 5/6 & 1 \\
TH 6/7 & 4 \\
TH 7/8 & 4 \\
TH 8/9 & 0 \\
TH 9/10 & 5 \\
TH 10/11 & 2 \\
TH 11/12 & 1 \\
TH 12/L1 & 3 \\
\hline
\end{tabular}

located, broad based, or extend transdurally. It seems common sense that residual herniated discs that cause neurological symptoms secondary to spinal cord and nerve root compression should be considered for reoperation.

Our main finding is that $90 \%$ of the patients reported improvement $(57 \%)$ or remained stable $(33 \%)$ after the primary surgery, which was in $100 \%$ of these cases a dorsal decompression in the form of either a laminectomy or hemilaminectomy. This occurred in spite of persistence of the pathologic entity. Apparently a sole dorsal decompression provided a short relieve for the spinal cord. This phenomenon has also been described by a French group where emergency laminectomy stabilized a deteriorating neurological condition followed by definite resolution via the anterior approach [5]. In our series-after a mean of 2.8 years - symptoms worsened again. The reason for this remains unclear. Possibly scar formation led to a recurrence of compression.

The concept of a dorsal decompression is well established in cervical myelopathy, especially in the form of multilevel anterior compression in OPLL or degenerative cervical spine disease. In the thoracic spine, however, different anatomical factors must be considered.

The protrusion is usually more pronounced in the midline rather than broad based posing the anterior spinal artery at greater risk [15].

Apparently, good or satisfactory clinical results gave the surgeons a false sense of success. This phenomenon is not exclusive to posterior approaches, but has been reported with anterior approaches as well [10]. Thorough analysis of the approach technique and possible alternatives in case of intraoperative unforeseen complications must play an important role when reoperating thoracic discs. Despite the wide availability of microscopes and endoscopes providing optimal magnification and bright illumination in narrow and deep seated areas, these are still not part of the standard equipment when treating this condition.
Optimal visualization of the mass-occupying lesion allowing a safe dissection and decompression and avoiding unnecessary dural sac manipulation should lead the surgical planning.

Despite the good results achieved with posterolateral approaches, there is wide consensus that for difficult cases the anterior techniques are prioritized [11]. The main reason for choosing this technique is related to better visualization and control of the anterior part of the spinal canal and ventral aspect of the dural sac. In posterior approaches, the ventral surface of the spinal canal or dura is often identified non-visually via angled instruments. Even if bilateral transpedicular or costotransversectomy approaches are used, the surgeon cannot visualize the ventral dural surface or the interface of the ventral midline dura and the pathological material. Ultrasound or navigation has been reported to aid in this situation $[16,17]$.

Although successful in a number of cases, especially in stabilizing an acute deteriorating neurological condition [5], we believe that this inadequate visualization and exposure (by failing to create a large working space in the vertebral body) contributed to the spinal cord injuries (SCIs) that the two patients sustained during the original operations in which the posterolateral approaches were performed, as reported by other groups [4, 11]. Transpedicular or posterolateral approaches may be indicated for the treatment of small, laterally positioned thoracic disc herniations [3, 18, 19]. However, the findings in our patients suggest that posterior or posterolateral approaches are less effective in achieving complete removal of large, centrally located and calcified discs.

An anterolateral approach provides direct, full visualization of the entire ventral surface of the dura and the ventral spinal cord. The anterior approach covers almost the entire dorsal spine, while mini thoracotomy provides a good working area up to the 5th thoracic vertebra, thoracoscopy allows to go even further cranial up to T2 [20]. The development of new instruments and refined surgical techniques has brought up alternative techniques to replace classic thoracotomy. Thoracoscopy $[10,21]$ or retropleural mini-open techniques (mini-TTA) [12, 22-25] have been reported with better results concerning post-operative pulmonary and shoulder dysfunction as well as post-thoracotomy pain syndrome [26-29]. Because of it, less demanding learning curve mini-TTA may be prioritized; however, in experienced and well-trained hands, thoracoscopy is the optimal technique when seeking for a less aggressive and equally effective alternative available nowadays [30].

As previously reported, video-assisted thoracoscopic surgery is an excellent technique for both primary and revision surgeries when treating herniated thoracic discs [31]. In addition to being associated with a lower morbidity rate and a faster recovery time than thoracotomy, 
(a)
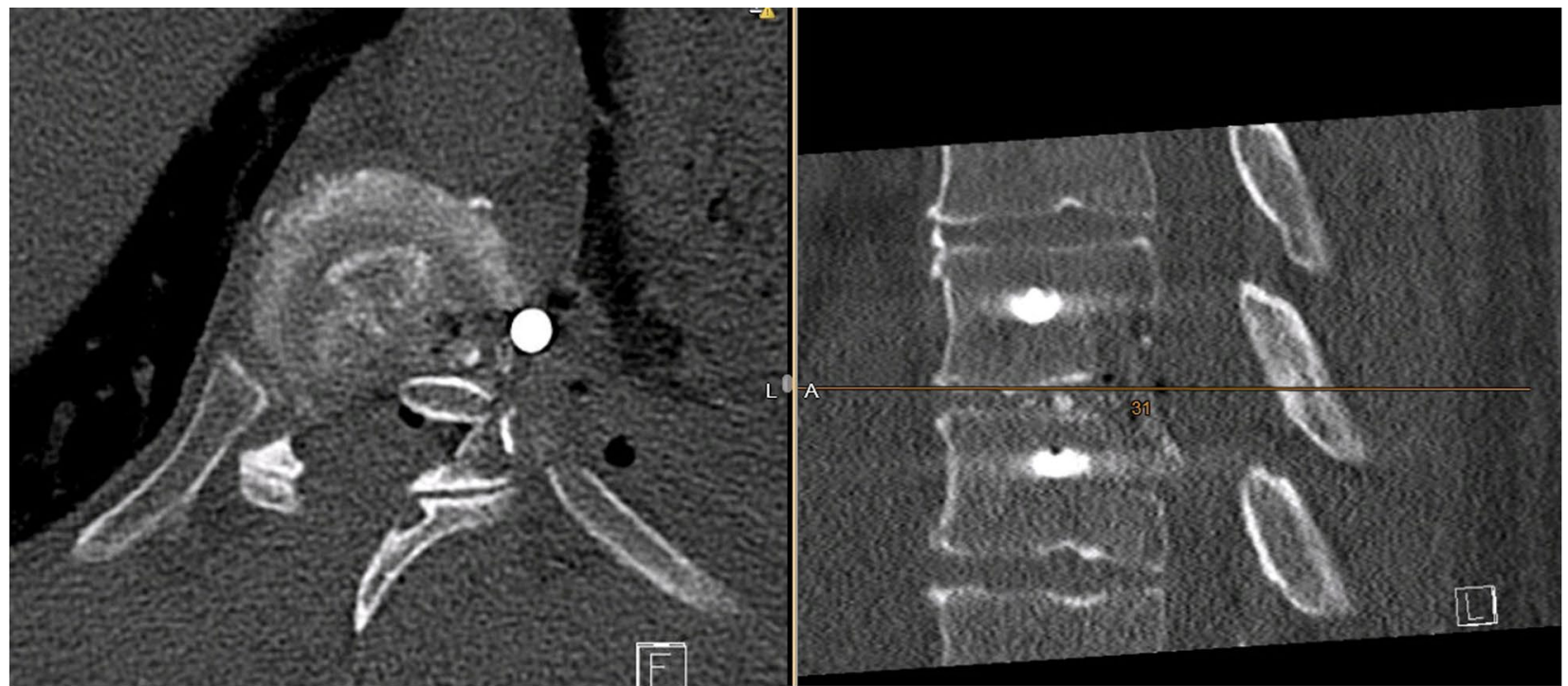

(b)
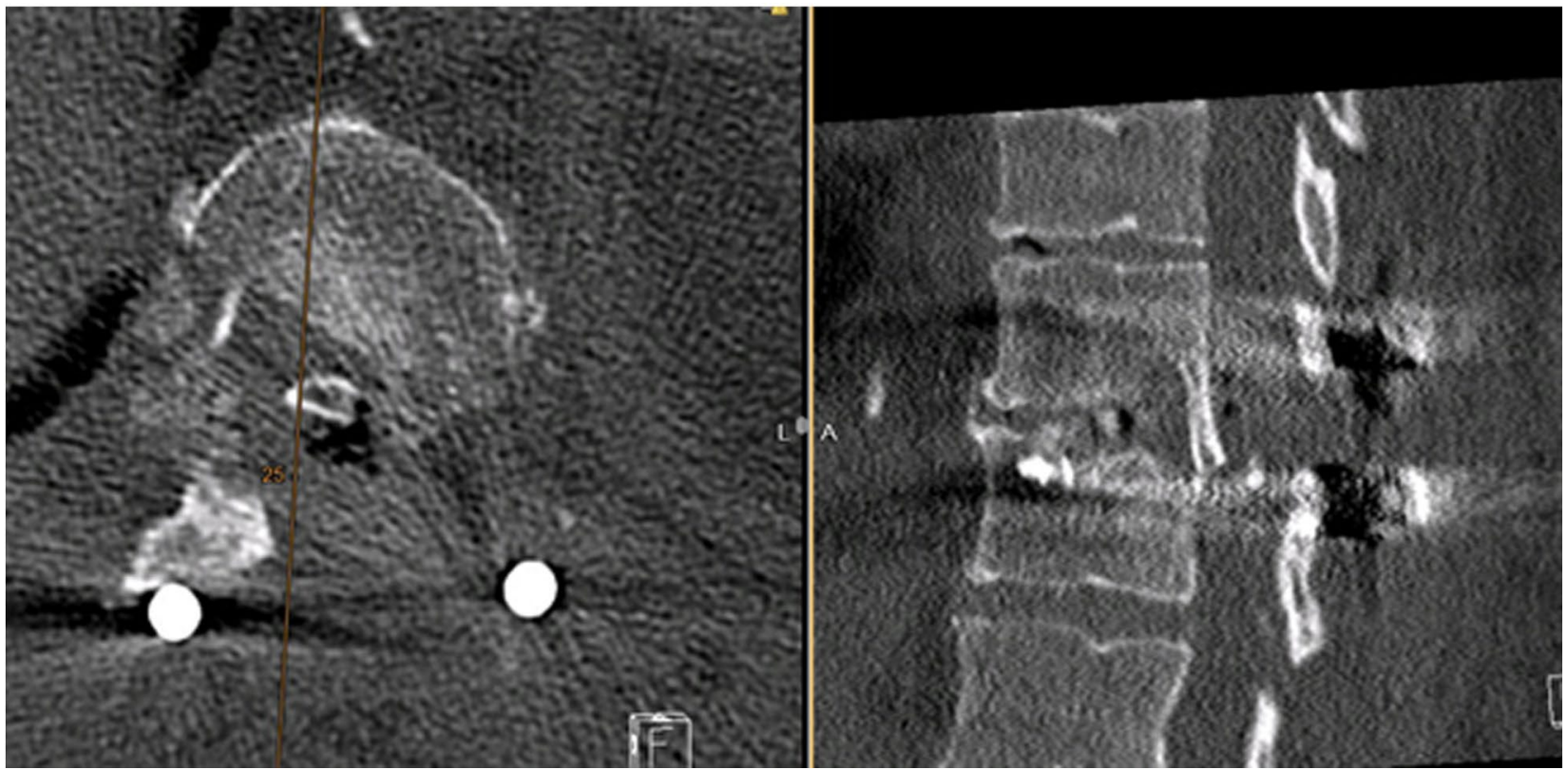

Fig. 2 a, b Two examples of post-operative CT scans corresponding to Fig. 1a, b. A bone piece is visible in the defect in both cases. The case of Fig. $1 \mathrm{~b}$ was also stabilized via laterally placed monoaxial screws in the vertebral body connected with a small rod

thoracoscopy-guided surgery provides direct access and visualization of the entire ventral surface of the spinal cord, facilitating dissection and decompression $[6,8,32]$.

Furthermore, residual compression or neurological worsening $[11,23]$ is not a phenomenon that occurs only in posterior approaches. Revision because of residual disc material has been reported in various series reviewing anterolateral approaches as well $[10,13,33]$. These cases were operated in the early stage of the technique. The availability of intraoperative $\mathrm{CT}$ imaging might prevent revision cases in future [10].

Modern spine surgery challenges the surgeons in tailoring approaches to the given case. The comfort zone must be on the patient's side and not on the surgeon's. Complex cases require a simple, highly effective approach with the lowest degree of complications the surgeon can offer.

Since introduction of the anterolateral approach 25 years ago-i.e. "the chop stick approach" (Ciaran Bolger), we still see reports emerging about the feasibility of variations of the posterolateral approach $[2,5,16,17,34,35]$, but for the time being and comparing results achieved with other procedures, the chop stick approach is "the technique to beat".

Only in the very rare cases in that the patient has undergone a prior thoracotomy, if dense lung adhesions are present, as well after prior pleurodesis or a previous empyema or hematothorax, or if the patient is unable to tolerate a single lung ventilation, a thoracoscopy is not well suited. 


\section{Historical perspective}

In our previous series 20 years ago, the two most common reasons for failure to remove a thoracic disc were mislocalization of the disc level and inadequate visualization of the pathological entity [36]. The latter principally reflects choosing the wrong route for operative exposure.

In this series, only one patient was operated on the wrong level. This might be explained by new and better procedures to recognize and mark the appropriate level intraoperatively (better radiological equipment) as well as the advancements achieved in intraoperative navigation and CT-based localizing techniques.

\section{Role of fusion}

We previously thought that most routine thoracic disc herniations do not require instrumentation and fusion because the facets, rib cage, and remaining thoracic spine adequately stabilize the spine [36]. However, if a partial corpectomyeven very small-is required to resect a thoracic disc, we experienced a large number of patients complaining about dorsal back pain. We attributed this to instability through the bony resection, as seen in other series [20]. Thus, every patient receives a fusion in form of a resected piece of bone bolstered by two laterally inserted monoaxial screws inserted into the vertebral bodies above and below the index segment, in agreement with other groups [12].

\section{Conclusions}

Our main finding is that $90 \%$ of the patients reported improved (57\%) or remained stable (33\%) after the primary surgery, which was in $100 \%$ of these cases a dorsal decompression in the form of either a laminectomy or hemilaminectomy. This occurred in spite of persistence of the pathologic entity. Apparently good or satisfactory clinical results gave the initial surgeon a false sense of security. Even if bilateral transpedicular or costotransversectomy approaches are used, the surgeon cannot visualize the ventral dural surface or the interface of the ventral midline dura and the pathological material.

These lesions require a ventral operative approach to obtain adequate visualization of the dura to resect the discs completely. Residual disc herniations that cause spinal cord or nerve root compression can cause progressive neurological deficits and should be treated with reoperation.

\section{Compliance with ethical standards}

Conflict of interest The authors report no conflict of interest.

Open Access This article is licensed under a Creative Commons Attribution 4.0 International License, which permits use, sharing, adaptation, distribution and reproduction in any medium or format, as long as you give appropriate credit to the original author(s) and the source, provide a link to the Creative Commons licence, and indicate if changes were made. The images or other third party material in this article are included in the article's Creative Commons licence, unless indicated otherwise in a credit line to the material. If material is not included in the article's Creative Commons licence and your intended use is not permitted by statutory regulation or exceeds the permitted use, you will need to obtain permission directly from the copyright holder. To view a copy of this licence, visit http://creativecommons.org/licenses/by/4.0/.

\section{References}

1. Yoshihara H, Yoneoka D (2015) Re: comparison of in-hospital morbidity and mortality rates between anterior and nonanterior approach procedures for thoracic disc herniation by Yoshihara et al. Spine (Phila Pa 1976) 40(17):E1001. https://doi.org/10.1097/ brs.0000000000001028

2. Borm W, Bazner U, Konig RW, Kretschmer T, Antoniadis G, Kandenwein J (2011) Surgical treatment of thoracic disc herniations via tailored posterior approaches. Eur Spine J 20(10):16841690. https://doi.org/10.1007/s00586-011-1821-7

3. Yi S, Kim SH, Shin HC, Kim KN, Yoon DH (2007) Outcome of surgery for a symptomatic herniated thoracic disc in relation to preoperative characteristics of the disc. Acta Neurochir (Wien) 149(11):1139-1145. https://doi.org/10.1007/s00701-007-1287-x. (discussion 1145)

4. Cornips EM, Janssen ML, Beuls EA (2011) Thoracic disc herniation and acute myelopathy: clinical presentation, neuroimaging findings, surgical considerations, and outcome. J Neurosurg Spine 14(4):520-528. https://doi.org/10.3171/2010.12.SPINE10273

5. Brauge D, Madkouri R, Reina V, Bennis S, Baussart B, Mireau E, Aldea S, Gaillard S (2017) Is there a place for the posterior approach in cases of acute myelopathy on thoracic disc hernia? World Neurosurg 107:744-749. https://doi.org/10.1016/j. wneu.2017.08.100

6. Rosenthal D, Rosenthal R, deSimone A (1994) Removal of a protruded thoracic disc using microsurgical endoscopy. A new technique. Spine (Phila Pa 1976) 19(9):1087-1091

7. Rosenthal D (2000) Endoscopic approaches to the thoracic spine. Eur Spine J 9(Suppl 1):S8-16

8. Rosenthal D, Dickman CA (1998) Thoracoscopic microsurgical excision of herniated thoracic discs. J Neurosurg 89(2):224-235. https://doi.org/10.3171/jns.1998.89.2.0224

9. Ruetten S, Hahn P, Oezdemir S, Baraliakos X, Godolias G, Komp M (2018) Operation of soft or calcified thoracic disc herniations in the full-endoscopic uniportal extraforaminal technique. Pain Phys 21(4):E331-E340

10. Cornips E, Habets J, van Kranen-Mastenbroek V, Bos H, Bergs P, Postma A (2017) Anterior transthoracic surgery with motor evoked potential monitoring for high-risk thoracic disc herniations: technique and results. World Neurosurg 105:441-455. https ://doi.org/10.1016/j.wneu.2017.05.173

11. Hott JS, Feiz-Erfan I, Kenny K, Dickman CA (2005) Surgical management of giant herniated thoracic discs: analysis of 20 cases. J Neurosurg Spine 3(3):191-197. https://doi.org/10.3171/ spi.2005.3.3.0191 
12. Uribe JS, Smith WD, Pimenta L, Hartl R, Dakwar E, Modhia UM, Pollock GA, Nagineni V, Smith R, Christian G, Oliveira L, Marchi L, Deviren V (2012) Minimally invasive lateral approach for symptomatic thoracic disc herniation: initial multicenter clinical experience. J Neurosurg Spine 16(3):264-279. https://doi. org/10.3171/2011.10.SPINE11291

13. Kapoor S, Amarouche M, Al-Obeidi F, U-King-im JM, Thomas N, Bell D (2018) Giant thoracic discs: treatment, outcome, and follow-up of 33 patients in a single centre. Eur Spine J 27(7):15551566. https://doi.org/10.1007/s00586-017-5192-6

14. Berjano P, Garbossa D, Damilano M, Pejrona M, Bassani R, Doria C (2014) Transthoracic lateral retropleural minimally invasive microdiscectomy for T9-T10 disc herniation. Eur Spine J 23(6):1376-1378. https://doi.org/10.1007/s00586-014-3369-9

15. Reynolds JM, Belvadi YS, Kane AG, Poulopoulos M (2014) Thoracic disc herniation leads to anterior spinal artery syndrome demonstrated by diffusion-weighted magnetic resonance imaging (DWI): a case report and literature review. Spine J 14(6):e17-e22. https://doi.org/10.1016/j.spinee.2013.10.050

16. Nishimura Y, Thani NB, Tochigi S, Ahn H, Ginsberg HJ (2014) Thoracic discectomy by posterior pedicle-sparing, transfacet approach with real-time intraoperative ultrasonography: clinical article. J Neurosurg Spine 21(4):568-576. https://doi. org/10.3171/2014.6.SPINE13682

17. Nakhla J, Bhashyam N, De la Garza Ramos R, Nasser R, Kinon MD, Yassari R (2018) Minimally invasive transpedicular approach for the treatment of central calcified thoracic disc disease: a technical note. Eur Spine J 27(7):1575-1585. https://doi.org/10.1007/ s00586-017-5406-y

18. Bilsky MH (2000) Transpedicular approach for thoracic disc herniations. Neurosurg Focus 9(4):e3

19. Arts MP, Bartels RH (2014) Anterior or posterior approach of thoracic disc herniation? A comparative cohort of mini-transthoracic versus transpedicular discectomies. Spine J 14(8):1654-1662. https://doi.org/10.1016/j.spinee.2013.09.053

20. Wait SD, Fox DJ, Jr, Kenny KJ, Dickman CA (2012) Thoracoscopic resection of symptomatic herniated thoracic discs: clinical results in 121 patients. Spine (Phila Pa 1976) 37(1):35-40. https ://doi.org/10.1097/brs.0b013e3182147b68

21. Quint U, Bordon G, Preissl I, Sanner C, Rosenthal D (2012) Thoracoscopic treatment for single level symptomatic thoracic disc herniation: a prospective followed cohort study in a group of 167 consecutive cases. Eur Spine J 21(4):637-645. https://doi. org/10.1007/s00586-011-2103-0

22. Moran C, Ali Z, McEvoy L, Bolger C (2012) Mini-open retropleural transthoracic approach for the treatment of giant thoracic disc herniation. Spine (Phila Pa 1976) 37(17):E1079-E1084. https ://doi.org/10.1097/brs.0b013e3182574657

23. Roelz R, Scholz C, Klingler JH, Scheiwe C, Sircar R, Hubbe U (2016) Giant central thoracic disc herniations: surgical outcome in 17 consecutive patients treated by mini-thoracotomy. Eur Spine J 25(5):1443-1451. https://doi.org/10.1007/s00586-016-4380-0

24. Deviren V, Kuelling FA, Poulter G, Pekmezci M (2011) Minimal invasive anterolateral transthoracic transpleural approach: a novel technique for thoracic disc herniation. A review of the literature, description of a new surgical technique and experience with first
12 consecutive patients. J Spinal Disord Tech 24(5):E40-E48. https://doi.org/10.1097/bsd.0b013e318220af6f

25. Kasliwal MK, Deutsch H (2011) Minimally invasive retropleural approach for central thoracic disc herniation. Minim Invasive Neurosurg 54(4):167-171. https://doi.org/10.1055/s-0031-12844 00

26. Dajczman E, Gordon A, Kreisman H, Wolkove N (1991) Longterm postthoracotomy pain. Chest 99(2):270-274. https://doi. org/10.1378/chest.99.2.270

27. Faciszewski T, Winter RB, Lonstein JE, Denis F, Johnson L (1995) The surgical and medical perioperative complications of anterior spinal fusion surgery in the thoracic and lumbar spine in adults. A review of 1223 procedures. Spine (Phila Pa 1976) 20(14):1592-1599

28. Ferson PF, Landreneau RJ, Dowling RD, Hazelrigg SR, Ritter P, Nunchuck S, Perrino MK, Bowers CM, Mack MJ, Magee MJ (1993) Comparison of open versus thoracoscopic lung biopsy for diffuse infiltrative pulmonary disease. J Thorac Cardiovasc Surg 106(2):194-199

29. Landreneau RJ, Hazelrigg SR, Mack MJ, Fitzgibbon LD, Dowling RD, Acuff TE, Keenan RJ, Ferson PF (1993) Thoracoscopic mediastinal lymph node sampling: useful for mediastinal lymph node stations inaccessible by cervical mediastinoscopy. J Thorac Cardiovasc Surg 106(3):554-558

30. Bartels RH, Peul WC (2007) Mini-thoracotomy or thoracoscopic treatment for medially located thoracic herniated disc? Spine (Phila Pa 1976) 32(20):E581-E584. https://doi.org/10.1097/ brs.0b013e31814b84e1

31. Gille O, Soderlund C, Razafimahandri HJ, Mangione P, Vital JM (2006) Analysis of hard thoracic herniated discs: review of 18 cases operated by thoracoscopy. Eur Spine J 15(5):537-542. https ://doi.org/10.1007/s00586-005-1014-3

32. Rosenthal D, Marquardt G, Lorenz R, Nichtweiss M (1996) Anterior decompression and stabilization using a microsurgical endoscopic technique for metastatic tumors of the thoracic spine. J Neurosurg 84(4):565-572. https://doi.org/10.3171/ jns.1996.84.4.0565

33. Oppenlander ME, Clark JC, Kalyvas J, Dickman CA (2013) Surgical management and clinical outcomes of multiple-level symptomatic herniated thoracic discs. J Neurosurg Spine 19(6):774-783. https://doi.org/10.3171/2013.8.SPINE121041

34. Ding WY, Guo Z, Zhang YZ, Shen Y, Li BJ, Zhang W, Chen HL (2009) Posterolateral transforaminal interbody fusion for thoracic disc herniation: a retrospective study of 38 cases. Orthop Surg 1(4):280-284. https://doi.org/10.1111/j.1757-7861.2009.00048.x

35. Wagner R, Telfeian AE, Iprenburg M, Krzok G, Gokaslan Z, Choi DB, Pucci FG, Oyelese A (2016) Transforaminal endoscopic foraminoplasty and discectomy for the treatment of a thoracic disc herniation. World Neurosurg 90:194-198. https://doi. org/10.1016/j.wneu.2016.02.086

36. Dickman CA, Rosenthal D, Regan JJ (1999) Reoperation for herniated thoracic discs. J Neurosurg 91(2 Suppl):157-162

Publisher's Note Springer Nature remains neutral with regard to jurisdictional claims in published maps and institutional affiliations.

\section{Affiliations}

\section{Stephan Dützmann ${ }^{1} \mathbb{D} \cdot$ Roli Rose $^{1} \cdot$ Daniel Rosenthal $^{1}$}

Stephan Dützmann

Stephan.duetzmann@gmail.com
1 Neurochirurgische Praxis, Zeppelinstr. 24, 61352 Bad Homburg, Germany 